\title{
Los antiguos en el Nuevo Mundo. Reflexiones de los jesuitas José de Acosta y Alonso de Ovalle sobre el origen de los nativos americanos, siglos XVI-XVII
}

\author{
Carolina Valenzuela Matus ${ }^{1}$ \\ Recibido: 14 de julio de 2017 - Aceptado: 25 de septiembre de 2017
}

\begin{abstract}
Resumen
Durante los siglos XVI y XVII, cronistas y evangelizadores europeos defendieron algunas teorías de poblamiento que sostenían que los nativos americanos provenían de pueblos bíblicos y grecorromanos. El objetivo de este artículo es analizar las reflexiones realizadas sobre esta materia por los jesuitas José de Acosta y Alonso de Ovalle, considerando que hubo un tiempo en que las exploraciones geográficas y un conocimiento más cabal del continente privilegió el valor de la evidencia y la experiencia. Este artículo pretende demostrar que los jesuitas aquí estudiados tuvieron una postura escéptica sobre estas teorías, adhiriendo a un método racional moderno desde el que realizaron sus propuestas sobre poblamiento, prescindiendo de la presencia de las antiguas civilizaciones pero manteniendo la idea del monogenismo bíblico.
\end{abstract}

Palabras clave: Monogenismo bíblico, tradición clásica, jesuitas, poblamiento.

\section{Ancients in the New World. Reflections by Jesuits} José de Acosta and Alonso de Ovalle about the origin of Native Americans, $16^{\text {th }}-17^{\text {th }}$ centuries

\begin{abstract}
During the Sixteenth and Seventeenth centuries, European chroniclers and evangelizers defended some settlement theories that held that Native Americans came from Biblical and Greco-Roman people. This article is aimed to analyze the reflections made on this subject by Jesuits José de Acosta and Alonso de Ovalle, considering that there was a time when geographical explorations and a more accurate knowledge of the continent privileged
\end{abstract}

1 Chilena. Doctora en Estudios del Mundo Antiguo, Universidad Autónoma de Madrid, España. Investigador Postdoctoral, Proyecto Fondecyt Postdoctorado 3160095, Instituto de Historia, Universidad Valparaíso, Chile. E-mail: cvalenzuelamatus@gmail.com 
the value of evidence and experience. This article tries to demonstrate that Jesuits here studied had a skeptical position on these theories adhering to a modern rational method from which they made their proposals on settlement, dispensing with the presence of ancient civilizations but maintaining the idea of biblical monogenism.

Keywords: Biblical monogenism, classic tradition, Jesuits, settlement.

\title{
Os antigos no Novo Mundo. Reflexões dos jesuítas José de Acosta e Alonso de Ovalle sobre a origem dos nativos americanos, séculos XVI-XVII
}

\begin{abstract}
Resumo
Durante os séculos XVI e XVII, cronistas e evangelizadores europeus defenderam algumas teorias de assentamentos que sustentavam que os nativos americanos procediam dos povos bíblicos e greco-romanos. 0 objetivo deste artigo é analisar as reflexões feitas sobre este assunto pelos jesuítas José de Acosta e Alonso de Ovalle, considerando que houve um tempo onde as explorações geográficas e um conhecimento mais preciso do continente privilegiaram o valor da evidência e da experiência. Este artigo pretende demonstrar que os jesuítas aqui estudados tiveram uma posição cética sobre essas teorias que aderiram a um método racional moderno a partir do qual eles fizeram suas propostas sobre o assentamento, prescindindo a presença de civilizações antigas, mas mantendo a ideia do monogenismo bíblico.
\end{abstract}

Palavras-chave: Monogenismo bíblico, tradição clássica, jesuítas, assentamento.

Desde el comienzo del proceso de descubrimiento y conquista de América, el legado de la antigüedad se hizo presente en la interpretación que los viajeros hicieron sobre lo que veían en el Nuevo Mundo. El mundo clásico constituyó una herramienta asombrosamente útil para la comparación de culturas alejadas temporalmente en tiempo y espacio. Diversos autores de los siglos XVI y XVII nos dieron ejemplos de ello; así vemos que para el Inca Garcilaso de la Vega, el Cuzco es "otra Roma", en La Araucana de Alonso de Ercilla, los araucanos poseen el valor de Marte y para Bernabé Cobo, los cóndores del sur de América son como los mitológicos grifos a la vez que los manatíes se confunden con sirenas propias de los poemas homéricos (Valenzuela, 2016). En estos ejemplos es posible apreciar que la tradición clásica fue utilizada como un elemento comparativo por los conquistadores europeos que buscaba hacer comprensibles los aspectos ininteligibles de las culturas americanas.

Encontramos también comparaciones de la realidad americana con la antigüedad más remota conocida principalmente gracias a la Biblia. Para 
Colón, la isla de Cipango se identificaba con la Ofir y Társis bíblica (Gil, 1989)², mientras que Jerónimo de Mendieta vio a Hernán Cortés como otro Moisés que había guiado a la nueva Israel a la Tierra Prometida (Brading, 1991). Para este franciscano, los mismos ejércitos españoles no tenían el aura de Roma, sino más bien se identificaban con los anfitriones de una nueva Israel, que vence a los enemigos mediante el favor de Dios (Phelan, 1972).

Durante los siglos XVI y XVII diversas crónicas e historias americanas contaron con la influencia de la antigüedad tanto en el estilo y la comparación. A través de esta influencia, buscaron dar respuesta a importantes interrogantes. De hecho, una de las mayores incógnitas de los europeos al llegar a América fue el origen de su poblamiento. Y dentro de este contexto, se preguntaron también si otros pueblos de la antigüedad como hebreos, romanos, griegos o cartagineses tuvieron conocimiento de este Nuevo Mundo con anterioridad a la llegada de españoles y portugueses, constituyéndose aquellos en los ancestros de los actuales nativos americanos.

En la búsqueda de respuestas a estas interrogantes, cronistas e historiadores acudieron rápidamente a los conocimientos bíblicos y a la Historia Antigua. No obstante, más que encontrar respuestas, se generaron más dudas sobre la presunta presencia de pueblos antiguos en América. Por ello, diversos autores como Agustín de Zárate, Bernardino de Sahagún, Pedro Mártir de Anglería o el franciscano Gregorio García, entre otros, expusieron y desarrollaron las diversas teorías que se conocieron en la época sobre el origen del poblamiento americano (Marzal, 1993)³.

Considerando la gran amplitud del tema elegido, este artículo quiere aportar en un ámbito muy concreto y centrar su análisis en las reflexiones que dos importantes jesuitas, José de Acosta y Alonso de Ovalle, realizaron sobre el origen de los nativos americanos. La elección de estos dos autores se fundamenta en lo siguiente: José de Acosta, en su Historia Natural y Moral de las Indias (1590), fue uno de los primeros en tratar el origen del poblamiento americano de una manera racional, muy cercano a una visión científica, además de él mismo ser un reconocido naturalista y precursor de las historias naturales en el ámbito jesuita americano, lo que inspiró a varios

2 Lo señala también Pedro Mártir en sus Décadas, libro I y Alonso de Ovalle en su Histórica Relación, libro IV, cap. II.

3 En el siglo XIX, el naturalista Juan Ignacio Molina realizó un completo ensayo donde sintetiza las teorías de los siglos XVI y XVII, a la vez que incorpora nuevo conocimiento proveniente de las exploraciones geográficas de su época. Véase Molina (1821), "Sulla propagazione succesiva del genere umano", en Memorie di storia naturale. Bolonia: Tipografía Marsigli, pp. 170-283. 
intelectuales de su orden a seguir en el desarrollo de esta disciplina ${ }^{4}$, entre ellos al chileno Alonso de Ovalle, quien, en su Histórica relación del reino de Chile (1646), aparte de dar cuenta de estas influencias, creó una valiosa obra informativa de Chile en el ámbito geográfico-natural pero también misional. En ambos jesuitas, es también evidente el influjo del mundo clásico y de las civilizaciones de la antigüedad, saberes adquiridos en años de sólida formación intelectual al interior de la Compañía de Jesús. Estos saberes se combinaron con un conocimiento de la naturaleza americana y la valorización de la experiencia, en una época donde el testimonio personal de un erudito poseía un peso especial correspondiente a una "primacía de la prueba científica completamente personalizada" (Safier, 2016: 116).

Para comprender a qué teorías hicieron referencia nuestros autores, primero presentaremos una síntesis de aquellas teorías de los siglos XVI y XVII que postulaban la presencia de los pueblos de la antigüedad en América. En segundo lugar, analizaremos las reflexiones que tanto José de Acosta como Alonso de Ovalle realizaron sobre el origen de los nativos americanos en sus respectivas historias. A través de este análisis identificaremos el escepticismo de estos jesuitas frente a las teorías anteriores, y el planteamiento de nuevas propuestas adhiriendo a un método racional que prescinde de la presencia de los antiguos pueblos bíblicos y greco-latinos en América pero manteniendo la idea del monogenismo bíblico.

\section{Pueblos antiguos y el origen de los nativos americanos, siglos XVI-XVII}

Siendo parte de una sociedad profundamente cristiana, los misioneros que viajaron a América estuvieron de acuerdo en sustentar una teoría basada en el monogenismo bíblico, es decir, que todos los seres humanos provenían primero de Adán, y luego de Noé. Los pueblos de América no podían quedar excluidos de este plan divino (Prieto, 2010). Por lo tanto, pese a la distancia geográfica, los nativos americanos debían provenir de los primeros habitantes mencionados por el libro del Génesis.

Peter Mason señala que la disrupción de una división tripartita existente, producida por el descubrimiento de América, alteró la imagen del mundo. La estable y cerrada cosmología de la antigüedad y la Edad Media dio paso al desafío de descubrir qué había más allá del mundo conocido. El descubrimiento de nuevos pueblos como los turcos o los amerindios planteÓ problemas para

4 Acosta inspiró también a religiosos como Juan Eusebio Nieremberg (1595-1658), Athanasius Kircher (1601-1680), Bernabé Cobo (1580-1657), Antonio Vieira (1608-1697), Juan Ignacio Molina (1740-1829), Francisco Javier Clavijero (1731-1787) o Juan de Velasco (1727-1792). 
las genealogías convencionales, las cuales derivaban las tres razas del mundo de los tres hijos de Noé: Ham, Shem y Japhet. Había un nuevo continente en esta representación, el cual tenía que ser acomodado dentro de los cambios geográficos y sistemas etnográficos (Mason, 1990: 18).

Esta representación del mundo fue adaptada pero no modificada; de esta forma, el monogenismo bíblico se mantuvo incuestionado entre los evangelizadores, aunque sí quedaba por determinar el origen y la forma en que pasaron los primeros habitantes de América. Diversos autores de los siglos XVI y XVII pusieron especial énfasis en que resultaba complejo formular una teoría única, ya que había un desconocimiento total del origen de estos pueblos y también de su historia, como lo señala Pedro Mariño de Lobera en su introducción a la Crónica del Reino de Chile (original de 1598), donde dice respecto a los naturales de las Indias que:

"Ni sabemos el origen, ni de qué parte, o por qué vía hayan aportado a estos reinos; y andamos conjeturando acerca desto, sin atinar con el rastro de la verdad, no con poco disgusto de los hombres políticos, y curiosos, solamente por faltar historias antiguas desta tierra (...). Y es esto de tanto inconveniente, que aun los que sabemos las cosas que han pasado de dos o tres mil años a esta parte entre los lacedemonios, atenienses y espartanos, y en otras regiones remotísimas, que nos tocan, solamente por la curiosidad y vigilancia que tuvieron en escribir historias; andamos a ciegas en las cosas que sucedieron ahora ochenta o noventa años en los mismos reinos que habitamos" (Mariño de Lobera, 1861: 44).

Como se puede apreciar en la cita, Pedro Mariño de Lobera se lamenta de saber tan poco del lugar donde habita, conociéndose muy bien, por otra parte, las historias de la antigüedad clásica y de otras antiguas regiones. Y los que creen adivinar el origen del poblamiento en cierta medida recurren a la antigüedad bíblica y clásica para buscar respuestas.

Una de las teorías que se conocían en la época vinculaba el origen de los nativos americanos con una supuesta emigración fenicio-cartaginesa a América. Al respecto, José de Acosta menciona que Plinio transmitió noticias de Cornelio Nepote acerca de las exploraciones de los cartagineses y esto podría haber inducido a considerar una remota emigración de este pueblo, reconocido en la antigüedad por sus amplios conocimientos de navegación.

Ciertamente, Acosta conocía exactamente la cita de Plinio en su Historia Natural y señalaba que, "cuando Cartago era una potencia pujante, Hannón bordeó la costa desde Gades hasta los confines de Arabia y narró por escrito su periplo, igual que Himilcón, enviado por la misma época para explorar las partes más remotas de Europa" (Plinio, 1995: II, 67, 169). No obstante para 
José de Acosta, conocer esta información no es un dato suficiente para creer en la emigración cartaginesa.

Para Miguel Morán, esta teoría "se presentaba como un argumento legitimador de la conquista, pues los derechos de Cartago pasaron a Roma, cuando la venció, y posteriormente a España a través de la bula de Alejandro VI. También se propusieron hipotéticas emigraciones fenicias -en las que se identificaba de forma parecidamente curiosa lo fenicio con lo español-y judías como el origen de la cultura prehispánica" (Morán, 2010: 149). ${ }^{5}$

Incluso en nuestros días, la llegada de una emigración fenicio-púnica resulta atractiva entre algunos aventureros contemporáneos que se han dedicado a probar a través de la recreación de las naves y la realización de rutas marítimas, que éstos tenían en su época la capacidad para atravesar el océano. ${ }^{6}$

Durante la época estudiada, se discutió también el origen hebraico de los habitantes de América, teoría que parecía estar bastante consolidada entre los evangelizadores. Algunos consideraban que el rey Salomón podría haber llegado con una poderosa flota a América, basándose en los hechos narrados en el libro primero de los Reyes. ${ }^{7}$ Asimismo, algunos basaron el origen hebraico de los nativos americanos en la creencia que éstos tenían en un diluvio universal, así como también el hecho de que los nativos de México parecían ver a Quetzalcóatl como un salvador. Al respecto, Jerónimo de Mendieta explica que:

"Quetzalcóatl era en realidad el Mesías que esperaban los judíos al levantarse contra el gobierno romano. Los indios eran los descendientes, no de los judíos del Viejo Testamento que fueron desterrados por los asirios, sino más bien de alguno de los judíos que escaparon después de la destrucción de Jerusalén por Vespasiano y Tito, en el año 71 de nuestra era" (Phelan, 1972: 44).

5 En el caso de España, Gloria Mora señala que el marqués de Mondéjar en su tratado De prima Hebraeorum in Hispaniam migratione, apunta la presencia de la lengua hebrea antes de la llegada de los romanos, lo que demostraría la existencia de colonias de judíos establecidas con anterioridad al nacimiento de Cristo y por tanto, no merecedoras de la expulsión decretada por los Reyes Católicos (Mora, 2010: 452).

6 Véase la exploración por el Atlántico que realizó Philip Beale en la réplica de un barco fenicio. En http://cnnespanol.cnn.com/2013/03/02/llegaron-los-fenicios-antes-a-america-quecolon/ Revisado el 15-VII-2017.

7 El libro primero de los Reyes 9, 26-28 dice: "El Rey Salomón construyó una flota en Esyón Guéber, que está cerca de Elat, a orillas del mar de Suf, en la tierra de Edom, Jiram envió a las naves a sus servidores, marineros, conocedores del mar, con los servidores de Salomón. Llegaron a Ofir y trajeron de allí cuatrocientos veinte talentos de oro que llevaron al rey Salomón". Recordemos que en aquella época algunos relacionaban América con Ofir. 
Gregorio García en su Origen de los Indios del Nuevo Mundo e Indias Occidentales (1607), conocía también esta teoría señalando sin embargo que estos judíos provendrían de España:

"Los primeros Pobladores de las Indias fueron de España, en tiempo del Rei Hespero, ò como parece sentir el P.M. Fr. Tomás Maluenda, en tiempo de Tubal, Hijo de Japhet, i Nieto de Noé: de quien todos afirman con Beroso, que fue el primero, que despues del Diluvio pobló en España" (García, 1729: 172).

Gloria Mora explica la intencionalidad política que esconde esta teoría; Beroso, mencionado en la cita anterior, era un sacerdote del templo de Bel en Babilonia de época de Alejandro Magno, que narró en tres libros la historia de Babilona desde los tiempos primitivos hasta la conquista de Alejandro. Supuestamente esta obra habría sido redescubierta por el historiador y fraile dominico Annio de Viterbo (c. 1432-1502). Según la autora:

"La relación de Annio de Viterbo con España comienza en el momento en que decidió dedicar el Libro II de las Antiquitates, que trata de las instituciones etruscas, a los Reyes Católicos: "ad christianissimos Hispaniarum reges Ferdinandum et consortem eius Elisabetham". El Libro XVII, el último, versa sobre "De primis temporibus et quattuor ac viginti regibus primis Hispaniae et eius antiquitate", y en él los Reyes Católicos aparecen como descendientes directos de Noé: aquí Annio recoge la fuente clásica que identificaba a los iberos con los tobelos, pueblo fundado por Túbal (F. Josefo, Antiquitates, I, 6,1). Orgullosos de la antigüedad que un erudito famoso como Annio confería a la nación, los historiadores españoles, salvo notables excepciones, dieron crédito a las ficciones del viterbense" (Mora, 1998:21).

Desde este punto de vista, el poblamiento sostenido desde los tiempos del mítico Túbal y el rey Hespero contribuía a un discurso legitimador de la conquista española, distinto a la simple llegada de los hebreos donde no se precisa el origen hispano. Curiosamente, la idea del origen hebraico de los nativos ya generó problemas en 1578, momento en que según Teodoro Hampe Martínez, un dominico, Francisco de la Cruz y su grupo de seguidores, fueron condenados a morir en la hoguera por defender la idea de que "Ios indios eran herederos de las tribus perdidas de Israel, pero caídos en un estado infantil y necesitados de la tutela de los españoles para conformar una nueva cristiandad" (Hampe, 1998: 42).

Por otra parte, tampoco se descartaba que los nativos del Nuevo Mundo procedieran de los antiguos griegos. Peter Mason nos recuerda que Pedro Sarmiento de Gamboa, en su Historia índica, 1572, postuló un continente pan Atlántico, asumiendo que los habitantes de América eran descendientes 
de los habitantes de las partes más occidentales de este imperio después de la inmersión de la Atlántida. Presentó también una segunda conexión asumiendo que Odiseo había navegado a través del Atlántico a Yucatán después de la caída de Troya (Mason, 2015: 51-52).

Sobre el posible origen griego de los habitantes del Nuevo Mundo encontramos también referencias en Gregorio García:

"Averiguando Yo en el Perù, si havia algunas antiguallas, o congeturas, por donde constase haver tenido los Indios letras, fui informado de un Español, que trataba en las Minas de Çamora (...) està una Peña alta con un pico, à bordo salido fuera, en cuia frente estan esculpidos quatro renglones, cada uno de vara i media de largo, cuias letras parecen Griegas" (García, 1729: 189).

Y sobre los que pudieran cuestionar que los indios no tenían letras, García explica que tal vez podrían haberlas perdido en algún diluvio así como los griegos las perdieron en algún tiempo, según dice Platón en su Timeo. ${ }^{8}$

Además de estas reflexiones aporta más pruebas, ya que señala que en unos edificios antiguos del Perú también se encontraron ciertas letras que parecían griegas y utiliza el testimonio de Platón en el Timeo refiriéndose a la costumbre de los griegos de cantar sus historias desde muchachos: "lo qual hacian los Indios de Nueva España, porque segun el P. Acosta, tenian los Mexicanos grande curiosidad, en que los Muchachos tomasen de memoria los parlamentos que hacian los Oradores y Retoricos Antiguos, i muchos Cantares, que componian sus Poetas" (García, 1729: 190). Y no deja escapar detalles simples como la costumbre de los griegos de traer las orejas horadadas y con pendientes, cualidad de la cual los indios del Perú, según él, también hacían gala.

La presencia de los griegos se explica asimismo por la desaparecida Atlántida. Para algunos, los actuales habitantes de América provendrían de los habitantes de esta misteriosa isla, mientras que para otros, el mismo nuevo continente podría ser la desaparecida Atlántida, bien conocida por el Timeo de Platón.

8 En el Timeo, un anciano sacerdote egipcio le dice al sabio Solón: "Pero entre vosotros y en los demás pueblos, apenas habéis adquirido el uso de las letras, y todas las cosas necesarias a los Estados cuando terribles lluvias, a ciertos intervalos, caen sobre vosotros como un rayo, y solo dejan sobrevivir hombres iliteratos y extraños a las musas, de manera que comenzáis de nuevo, y os hacéis niños sin saber nada de los sucesos de este país o del vuestro, que se refieran a los tiempos antiguos" (Platón, 1872). 
Junto a la posible migración fenicio-cartaginesa, el origen hebreo y griego, estuvo la propuesta de que existiera un antiguo poblamiento romano en América que era posible observar por las cercanías de las costumbres entre los antiguos romanos y los indios del Nuevo Mundo. Al respecto, García señala algunos ejemplos como el uso del bermellón: "Quanto á lo primero, los Romanos celebraron, i tuvieron en mucho el Bermellon, teniendolo por color sagrado, como refiere Plinio, i asi dice, que solian teñir con él el Rostro de Jupiter, i los cuerpos de los que triunfaban" (García, 1729: 177). Y al respecto comenta que los Indios del Perú tenían una costumbre bastante parecida ya que "labraron gran tiempo las Minas del Açogue, sin saber del Açogue, ni conocerle, ni pretender otra cosa, sino este Bermellon, que ellos Ilaman Llimpi, el cual preciaban mucho para el mismo efecto que Plinio ha referido de los Romanos, que es para pintarse, ò teñirse con èl los rostros, i cuerpos suios, i de sus Idolos" (García, 1729: 178).

Este autor encuentra otra similitud en los monasterios de Doncellas y Vírgenes existentes en el Perú, los que son semejantes al de las Vestales de Roma donde recurre a las descripciones presentes en las obras de Gómara, Acosta y Torquemada. También compara los templos del Sol que habían en el Perú con el Panteón de Roma. Lo mismo sucede con los caminos y calzadas romanas "muy semejantes à los que havemos referido de los Romanos, mandaron hacer los Ingas, Reies del Perú" (García, 1729: 186). Gregorio García se refiere a los extensos caminos incas que se encontraban a lo largo de todo el imperio o Tahuantinsuyo y los compara con las vías romanas: "de manera que como en España hacian los romanos division de toda ella, por Provincias: asi los Ingas, i sus Vasallos, para contar las que havia en Tierra tan grande, lo entendian por sus caminos" (García, 1729: 186).

\section{Reflexiones sobre el poblamiento de América en José de Acosta y Alonso de Ovalle}

Tanto José de Acosta como Alonso de Ovalle conocieron cabalmente las teorías que se manejaban durante la época sobre el origen de los nativos del Nuevo Mundo. Acosta publicó en 1588 De natura novi orbis y de la extensión de ésta nació la Historia Natural y Moral de las Indias, publicada en 1590 en Sevilla. Por otra parte, Alonso de Ovalle publicó la Histórica Relación del Reino de Chile, y de las missiones y ministerios que exercita en la Compañia de lesus en 1646 en Roma. Pese a la diferencia temporal que separa a estos jesuitas, ambos realizaron un trabajo erudito donde se privilegia la descripción, la experiencia y la referencia a autoridades tanto clásicas como modernas.

José de Acosta en su Historia Natural y Moral de las Indias es consciente de la existencia de una serie de teorías que relacionan el poblamiento americano 
con la antigüedad pero se muestra escéptico y no adhiere a ninguna teoría definitiva, teniendo claro que se trata de una cuestión difícil de averiguar por falta de fuentes.

Sobre si hubo entre griegos y romanos conocimiento del Nuevo Mundo, Acosta señala que de lo que dice Plinio y otros intelectuales de la antigüedad, no se encuentran evidencias fehacientes que indiquen que los antiguos griegos y romanos tuvieran conocimiento de esta tierra: aunque Plinio trasmita noticias de Cornelio Nepote acerca de las exploraciones de los cartagineses, esto no prueba la existencia de América en los escritos clásicos, ya que según el jesuita, "apenas se halla cosa cierta en los libros de los escritores antiguos" (Acosta, 2008: 24).

Había otro asunto que incomodaba a Acosta con la idea de que griegos y romanos ya hubiesen conocido el Nuevo Mundo: cree que quienes buscan encontrar pistas de que los antiguos conocieron este territorio pretenden "menoscabar en esta parte la felicidad de nuestros tiempos y oscurecer la gloria de nuestra nación" (Acosta, 2008: 23). Acosta menciona que el descubrimiento de las Indias Occidentales habría sido profetizado por Séneca, lo que se lee en su tragedia Medea, aunque no realiza juicios sobre esta creencia. Los versos proféticos serían los siguientes:

"Tiempos vendrán al paso de los años

en que suelte el océano las barreras del mundo

y se abra la tierra en toda su extensión

y Tetis nos descubre nuevos orbes

y el confín de la tierra ya no sea Tule" (Séneca, 2010: 375).

Es sabido que la interpretación de la tragedia Medea como una profecía del descubrimiento de América fue utilizada por los conquistadores como un elemento más para la justificación de la conquista. Es importante recordar que Séneca era de origen hispano y por lo tanto, fue visto como un autor clásico que se entroncaba en la tradición española del siglo XVI.

Hacia el final del libro I, José de Acosta especula sobre posibles respuestas al origen del poblamiento. Al respecto, reconoce dos problemas: en primer lugar, la inmensidad del océano impediría habitar estas tierras; en segundo lugar, mantiene firmemente la creencia de que todos descendemos del primer hombre, es decir, adhiere al monogenismo bíblico defendido por los evangelizadores. Lo primero estaría probado por los descubrimientos geográficos, lo segundo, es una verdad mostrada por las Sagradas Escrituras. Aquí encontramos dos elementos muy propios de la época en que escribe el jesuita: se combina el interés por las evidencias que proporcionan los descubrimientos de la Edad Moderna con la Fe que debe incluir a América en el plan trazado por Dios para la salvación humana (Prieto, 2010). 
Para Acosta no es fácil imaginar el origen de este poblamiento y sus propuestas están guiadas, como él mismo dice, "por el hilo de la razón" (Acosta, 2008, 30). De esta manera, considera las siguientes opciones: la llegada de gentes por mar, por tierra, y en el caso de venir por mar, ver si fue por propia voluntad o bien por un naufragio. Para Acosta, la limitante para la navegación voluntaria es el desconocimiento de la piedra imán por parte de los antiguos. Por lo tanto, los primeros pobladores podrían haber llegado empujados por las tormentas, pero aún queda explicar cómo pasaron los animales, y de allí que el jesuita formula la siguiente propuesta:

"El nuevo orbe que llamamos Indias, no está del todo diviso y apartado del otro orbe. Y por decir mi opinión, tengo para mí días ha que la una tierra y la otra se juntan y continúan; 0 , a lo menos, se avecinan y allegan mucho" (Acosta, 2008: 36).

Esta sería una explicación sobre cómo se habría ido poblando el continente americano, pues gentes y animales irían pasando beneficiados por la vecindad de tierras entre los continentes. Por estas ideas, hay especialistas que han creído encontrar en Acosta el precursor de las actuales teorías del poblamiento americano, sin embargo, Andrés Prieto señala que la exposición de Acosta sobre el poblamiento del continente no fue una idea original y simplemente repitió el argumento avanzado por Juan López de Velasco en su Geografía y descripción universal de las Indias (Prieto, 2010). Por otra parte, para el autor recién citado, el origen de la población americana fue más un desafío teológico que un misterio antropológico para Acosta, ya que debía seguir el libro del Génesis e incorporar a los nativos dentro del contexto judeo-cristiano.

También para Fermín del Pino el hecho de considerar a Acosta como un precursor de la teoría del estrecho de Bering es ir un poco lejos ya que prescinde del texto comentado o se saca de contexto. Por otra parte, para el autor, Acosta sostiene que América habría sido poblada por el sur y no por el norte como se suele pensar:

"Acosta propone en realidad seguir el modelo propuesto por los mapas contemporáneos, y en particular el de Abraham Ortelius -traducido en el año 88 recientemente, con dedicatoria a Felipe II- donde la "terra australis" situada al otro lado del Estrecho de Magallanes se continúa con las islas de Salomón" (Pino Díaz, 2008: XVIII).

El jesuita Alonso de Ovalle en su Histórica Relación del Reino de Chile (1646), conocedor de la propuesta de Acosta9 ${ }^{9}$, descartó la unión de tierras

9 Ovalle demuestra conocer bien la obra de Acosta aunque Walter Hanisch señala que solo la conoció en latín en los dos primeros libros de De Natura novi orbis libri duo et de 
por el sur, basado principalmente en las nuevas exploraciones geográficas del siglo XVII, como se constata en esta cita:

"Abrahán Ortelio [en su obra Theatrum orbis terrarum] quiso decir, que por esta parte del Sur le avecindaba a Chile una Tierra, que se continuaba con la nueva Guinea, y duró esta opinión hasta que supimos el desengaño de los que habiendo pasado al mar del sur por el estrecho de San Vicente (...) bordeando toda la tierra Austral que se dice del fuego, y volviendo al mar del norte por el estrecho de Magallanes, probaron evidentemente, que dicha tierra era isla, separada del todo de cualquiera otra" (Ovalle, 2012: 1).

Por lo tanto, para Ovalle, la propuesta de José de Acosta no tiene más valor que el de "un raçonable discurso" (Ovalle, 2012: 81). De esta manera se descarta el poblamiento por el sur aunque el jesuita explica que se desconoce todavía si por el oriente, la tierra en frente de Tierra del Fuego, pueda avecindarse a África y que desde allí pudieran pasar pequeñas embarcaciones.

Para Ovalle, al igual que para José de Acosta, la región de América estuvo oculta "a los ingenios más linces, a los Aristoteles, Parmenides y Plinios, y entre los philosophos cristianos, a S. Agustin, Lactancio y otros que juzgaron por inhabitable, o impenetrable todo lo que del tropico de Cancrio adelante pudieron contemplar" (Ovalle, 2012: 106).

Por lo tanto, Ovalle tampoco cree posible que los antiguos romanos tuvieran conocimiento del Nuevo Mundo aunque aquellos que defendían esta teoría "entraron en él fundándose en la moneda de Augusto César que se halló en las minas, porque parece increíble, que habiéndole una vez descubierto, se perdiese después tan del todo su comunicación, y aun su memoria" (Ovalle, 2012: 109).

La falta de evidencia hace este argumento poco creíble. La moneda de Augusto César que dicen haber encontrado en las minas ha desaparecido y bien podría tratarse de alguna antigüedad trasladada allí por alguien. Y si los romanos no conocieron América tampoco lo hicieron las flotas del rey Salomón, y aunque Ovalle alaba las virtudes de tan sabio rey, es consciente de la falta de pruebas que lo vinculan a América.

Un aspecto relevante de la obra de Alonso de Ovalle es que se refiere también al origen sostenido por los propios nativos, el que se remonta a un diluvio, que para el jesuita no es el diluvio universal bíblico, pues según sus mitos, habrían quedado algunos pobladores en las tierras altas. Ovalle

promulgatione evangelii apud barbaros, sive de procuranda indorum salute libri sex. Véase Hanisch, 1976. 
comenta que los nativos "no tuvieron la dicha de haber visto el capítulo de el Exodo donde huvieran hallado el desengaño de su ignorancia, pues como del consta, fuera del Arca de Noe no quedò hombre, ni viviente alguno en toda la tierra" (Ovalle, 2012, 79).

El modo en que Noé pasó su descendencia a estas tierras era difícil de averiguar; incluso, señala que algunos europeos creyeron en que los antepasados de los nativos provendrían de la Atlántida según lo descrito en el Timeo de Platón, argumento ya mostrado por Acosta, lo mismo que la descendencia de los hebreos basada en la similitud de costumbres, sin embargo Ovalle, al igual que Acosta, las ve como teorías sin fundamento. Incluso los que creen la llegada de Santo Tomás a América, no encuentran pruebas para sostenerla y es así que llega a la conclusión de que "Guardava Dios a la nacion española la gloria de ilustrar a aquel mundo con la luz del santo Evangelio" (Ovalle, 2012: 328).

El descubrir el nuevo continente se convierte en un acto providencialista donde el protagonismo lo tiene España, al igual como hiciera Acosta donde se queja de aquellos que restan gloria al imperio español, entregándole a los antiguos pueblos bíblicos y de la antigüedad clásica el mérito de haberse constituido en el origen del Nuevo Mundo.

\section{Reflexiones finales}

Hemos analizado las reflexiones que tanto José de Acosta como Alonso de Ovalle realizaron en sus respectivas historias sobre las teorías de la época que consideraban a los pueblos de la antigüedad bíblica y grecorromana como el origen de los nativos americanos.

Tanto en José de Acosta como en Alonso de Ovalle se observa un conocimiento cabal de la materia del origen del poblamiento americano y unas claras reflexiones conducidas por la racionalidad. Estos razonamientos prestan especial atención a las evidencias o registros que prueben la presencia de los pueblos de la antigüedad en América. Como no hay rastros de éstos, las teorías quedan descartadas justamente por la falta de evidencias. No obstante, rechazar la presencia de los antiguos también conlleva un compromiso ideológico y político con el imperio español. Para José de Acosta, fue a España a quien le correspondió descubrir este Nuevo Mundo y en el mismo sentido Alonso de Ovalle destaca que la gran tarea de la evangelización en América también estuvo reservada a esa nación.

Los razonamientos de ambos jesuitas se enmarcan necesariamente dentro de las enseñanzas bíblicas y en ningún momento se cuestiona la teoría monogenista, muy por el contrario, los argumentos racionales buscan incluir 
a los nativos en el plan universal de Dios y en la tradición del génesis bíblico, por lo tanto, las teorías propuestas deben encaminarse a probar lo que está dictaminado en las Sagradas Escrituras.

En la búsqueda de respuestas sobre el origen del poblamiento del Nuevo Mundo, José de Acosta planteó una teoría que ha sido vista por algunos como el origen de las actuales teorías del poblamiento americano: basándose en el mapa de Abraham Ortelius, Acosta propuso que los primeros habitantes del continente habrían llegado por mar, impulsados por tormentas, o bien por tierra, ya que América no era completamente indivisa. Sin embargo, Alonso de Ovalle descartó este poblamiento por el sur ya que los últimos descubrimientos habían probado que por esa zona el territorio se dividía. Vemos en este caso que, el conocimiento de Ovalle sobre las exploraciones geográficas del siglo XVII, contribuyó a la reflexión sobre el origen del territorio americano y sus habitantes.

Ambos autores coinciden en que aquellos que defienden la idea de que hebreos, griegos y romanos poblaron el continente fundamentaron sus teorías en la similitud de costumbres entre los pueblos de la antigüedad y los nativos americanos. Los religiosos e intelectuales que pensaron en esta posibilidad recurrieron a su conocimiento de la antigüedad y de la tradición clásica, utilizando a autores como Platón, Aristóteles, Séneca o Plinio, entre otros que comenzaron a difundirse gracias al renacimiento europeo y que por tanto constituían una tradición conocida por aquellos que escribieron sobre materias americanas.

Esta similitud de costumbres que los jesuitas vieron entre los nativos y los griegos o romanos de la antigüedad nació del uso que cronistas y evangelizadores hicieron de los autores antiguos para interpretar el Nuevo Mundo. A través de ellos se buscan analogías utilizando una cultura ya conocida, la grecolatina, para interpretar las costumbres de los pueblos americanos. Como señala Peter Mason, cualquier observación de otras gentes y culturas está ligada a las limitaciones de los observadores humanos que clasifican antes de ver, reduciendo la clasificación a un área conocida; esto explica por qué los europeos buscaron en la tradición greco-romana para describir a las gentes del Nuevo Mundo (Mason, 1994: 138).

Es importante recordar que el poblamiento del hombre americano sigue siendo un problema tan insoluble hoy como lo fue en los siglos XVI y XVII. Aunque se han formulado teorías desde el ámbito científico que son ampliamente aceptadas, resulta necesario volver atrás la mirada para valorar la importante influencia ejercida por la antigüedad bíblica y clásica en las teorías aportadas por los intelectuales de los siglos XVI y XVII, así como también los debates en torno a su veracidad, representado por jesuitas como José de Acosta y Alonso de Ovalle, que gracias a su esmerada formación intelectual, pensaron el Nuevo 
Mundo no tan solo desde los clásicos sino que incorporaron también la racionalidad moderna y el nuevo conocimiento geográfico desde donde refutaron las teorías de otros religiosos y cronistas para plantear sus respectivas propuestas y reflexiones sobre el poblamiento de América.

\section{Referencias bibliográficas}

\section{a) Artículos}

Alberti, P. (1987). "Mujer y religión: Vestales y Acllacuna, dos instituciones religiosas de mujeres", en Revista Española de Antropología Americana, №18, pp. 155-196.

Mason, P. (1994). "Classical Etnography and Its Influence on the European Perception of the Peoples of the New World", en Haase, W. y Reinhold, M. (eds.), The Classical Tradition and the Americas Part I. Berlín: Walter de Gruyter, p. 138.

Prieto, A. (2010). "Reading the book of Genesis in the New World: José de Acosta and Bernabé Cobo on the origins of the American Population", en Hispanófila, vol. 158, pp. 1-19.

\section{b) Libros}

Acosta, J. (2008). Historia Natural y Moral de las Indias. Edición crítica de Fermín del Pino Díaz. Madrid: Consejo Superior de Investigaciones Científicas.

Brading, D. (1991). Orbe Indiano. De la monarquía católica a la República criolla, 1492-1867. México: Fondo de Cultura Económica.

García, G. (1729). Origen de los indios de el Nuevo Mundo e Indias Occidentales. Original 1607. Madrid: Imprenta de Francisco Martínez Abad.

Gil, J. (1989). Mitos y utopías del Descubrimiento. Madrid: Alianza Editorial.

Hanisch, W. (1976). El historiador Alonso de Ovalle. Caracas: Universidad Católica Andrés Bello.

Josefo, F. (1997). Antigüedades Judías, libros I- XI, edición de José Vara Donado, Madrid: Akal.

Josefo, F. (1997). Antigüedades Judías, libros XII- XX. Edición de José Vara Donado, Madrid: Akal.

Mariño de Lobera, P. (1861). Crónica del Reino de Chile. Original de 1598. Colección de Historiadores de Chile y documentos relativos a la historia nacional. Santiago de Chile: Imprenta del Ferrocarril. 
Marzal, M. (1993). Historia de la Antropología Indigenista. México y Perú. Barcelona: Anthropos.

Mason, P. (1990). Deconstructing America. Representations of the Other. London: Routledge.

Mason, P. (2015). The Ways of the World: European representations of other cultures: from Homer to Sade. Canon Pyon: Sean Kingston Publishing.

Mora, G. (1998). Historias de mármol. La arqueología clásica española en el siglo XVIII, Anejos de Archivo Español de Arqueología XVIII. Madrid: Centro Superior de Investigaciones Científicas.

Morán, M. (2010). La memoria de las piedras. Anticuarios, arqueólogos, y coleccionistas de antigüedades en la España de los Austria. Madrid: Centro de Estudios Historia Hispánica.

Ovalle, A. (2012). Histórica Relación del Reino de Chile, y de las missiones y ministerios que exercita en la Compañia de lesus (1646). Santiago de Chile: Edición Facsimilar El Mercurio.

Phelan, J. (1972). El Reino Milenario de los Franciscanos en el Nuevo Mundo. México: Universidad Nacional Autónoma de México.

Platón (1872). Obras completas. Edición de Patricio Azcárate. Madrid: Tomo 6, en http://www.filosofia.org/cla/pla/img/azf06131.pdf Revisado el 30-V-2016.

Plinio el Viejo (2002). Historia Natural. Edición de Josefa Cantó, Isabel Gómez Santamaría, Susana González Marín y Eusebia Tarriño. Madrid: Cátedra.

Plinio el Viejo (1995). Historia Natural. Libros I, II. Introducción General de Guy Serbat. Madrid: Gredos.

Sagrada Biblia (1985). Versión directa de las lenguas originales. Ed. de E. Nácar y A. Colunga. XXXVIII edición. Madrid: La Editorial Católica.

Séneca (2010). Medea. Presentación y traducción de Jesús Luque Moreno. Madrid: Gredos.

Valenzuela, C. (2016). Grecia y Roma en el Nuevo Mundo. La recepción de la antigüedad clásica en cronistas y evangelizadores del siglo XVI americano. Barcelona: Rubeo. 